\title{
Chitosan Nanoparticles for Antiviral Drug Delivery: A Novel Route for COVID-19 Treatment
}

\author{
Abdel-Majed Safer $\mathbb{D}^{\prime}$ \\ Stefano Leporatti $\mathbb{D}^{2}$ \\ 'Department of Biological Sciences, \\ Faculty of Science, Kuwait University, \\ Kuwait City, Kuwait; ${ }^{2}$ CNR Nanotec, \\ Istituto di Nanotecnologia, Lecce, 73100, \\ Italy
}

\begin{abstract}
Chitosan has been investigated in several biological fields, including drug and gene delivery, tissue engineering antiviral and immunological adjuvant methods. It's a cationic copolymer of $\mathrm{N}$-acetyl glucosamine and D-glucosamine with different molecular chain lengths, compositions, and sequences than $\mathrm{N}$-acetyl glucosamine and D-glucosamine. It is biocompatible and cyto-compatible, as well as recyclable and bioresorbable. As effective drug delivery methods, chitosan nanoparticles are shaped into several pathways. The purpose of this article is to provide an overview of its antiviral application as a nanocarrier for antiviral medications, highlighting the benefits, limitations, and downsides. In this review, we will report the most recent COVID-19 vaccination advances. It will also be discussed what the future holds for chitosan nanoparticles in the treatment of coronaviruses.
\end{abstract}

Keywords: chitosan, nanoparticles, drug delivery, antivirals, COVID-19

\section{Introduction}

According to research conducted in many labs in the field of nanotechnology, particularly in nanomedicine, it appears that nanotechnology and nanomedicine should play an active role in treating and preventing the spread of Coronavirus Infectious Disease-19 (COVID-19). ${ }^{1-6}$ Polymeric nanoparticles, such as chitosan NPs, ${ }^{7}$ are one of the possibilities available for this purpose, depending on the type of the nanoparticles utilized in therapeutic treatment. A valid hypothesis, based on our recent publication on Conjugation of Epigallocatechin gallate (EGCG) and Chitosan Nanoparticles (NPs) ${ }^{8}$ would be to expand on the benefits and strengthen the use of chitosan as a nanocarrier for antiviral drug delivery (as explored only in a few examples like (Ramana et $\mathrm{al}^{7}$ ) against future novel coronaviruses. Colloidal particles that can be dissolved, entrapped, encapsulated, or adsorbed onto the constituent polymer matrix could be employed in vaccinations or medicinal agent delivery systems. Chitosan is part of the group formed from natural or synthetic polymers such the poly (lactide-co-glycolide) (PLGA) family, which also includes polylactide (PLA), polyglycolide (PGA), polycaprolactone (PCL), poly (D, L-lactide), and PLGA-polyethylene. ${ }^{9,10}$ Polyethylene glycol (PEG) is one of these alternatives. These polymers are among the few synthetic polymers allowed by the US Food and Drug Administration (FDA) due to their biodegradability and biocompatibility. ${ }^{11,12}$ A range of experimental polymeric administration systems have been developed over the last 20 years. Antiviral polysaccharides with good safety, immunological modulation, and antiviral efficacy have a wide range of applications (see Figures 1-3), particularly in anti-coronavirus applications. ${ }^{13,14}$
Correspondence: Abdel-Majed Safe Department of Biological Sciences, Faculty of Science, Kuwait University, Kuwait City, Kuwait

Tel +96524985909

Email saferam52@gmail.com

Stefano Leporatti

CNR Nanotec, Istituto di

Nanotecnologia, Lecce, Italy

Tel +390832319829

Email stefano.leporatti@nanotec.cnr.it 


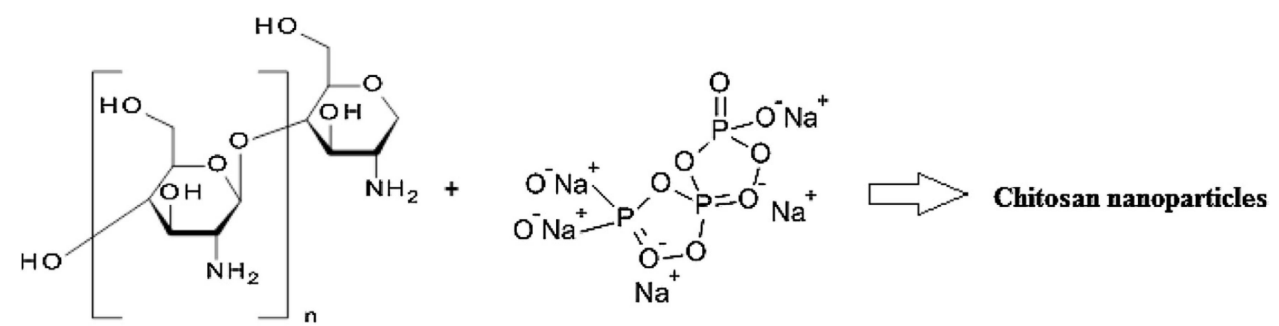

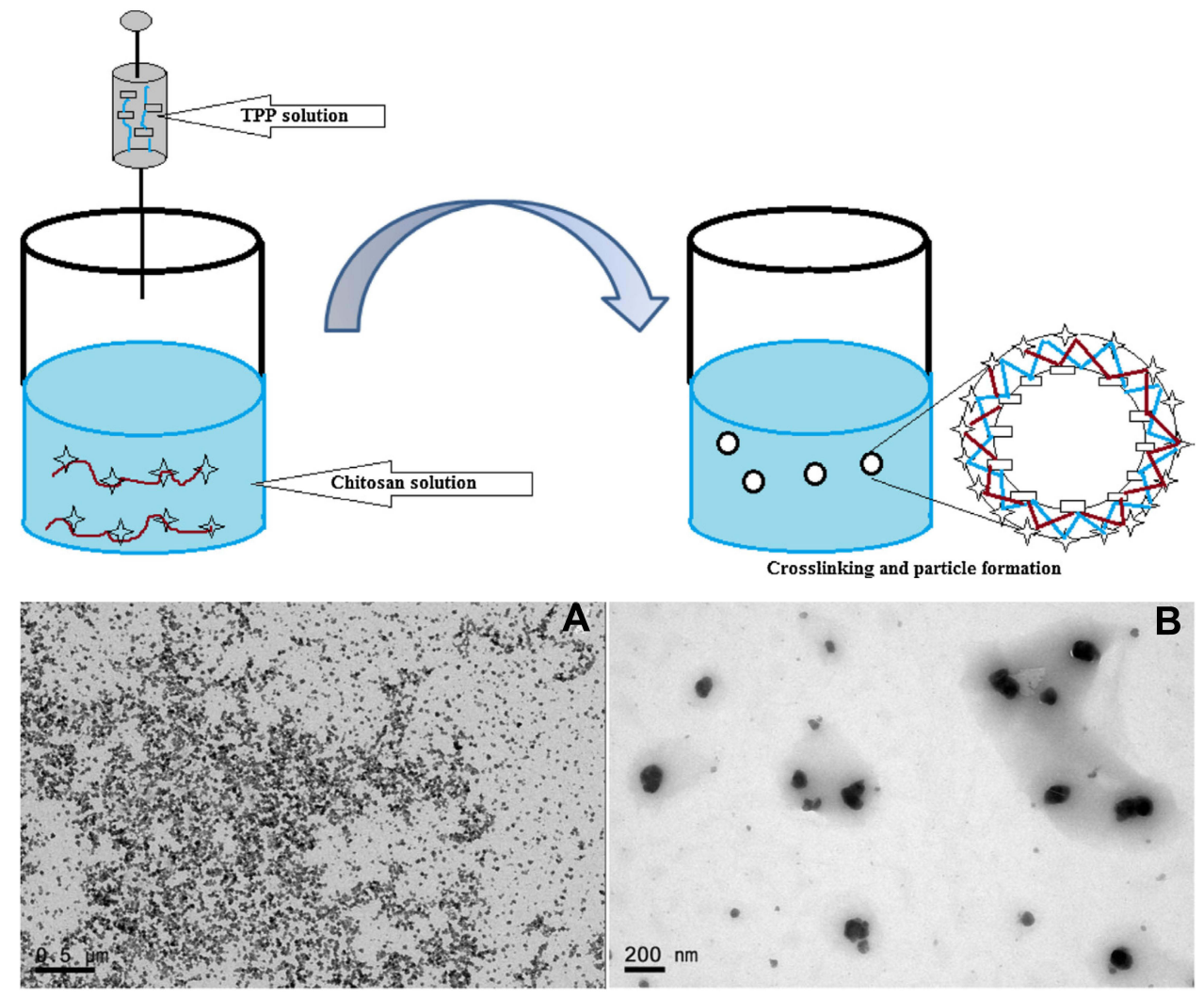

Concentration - Time Curve of 4109

in Rats

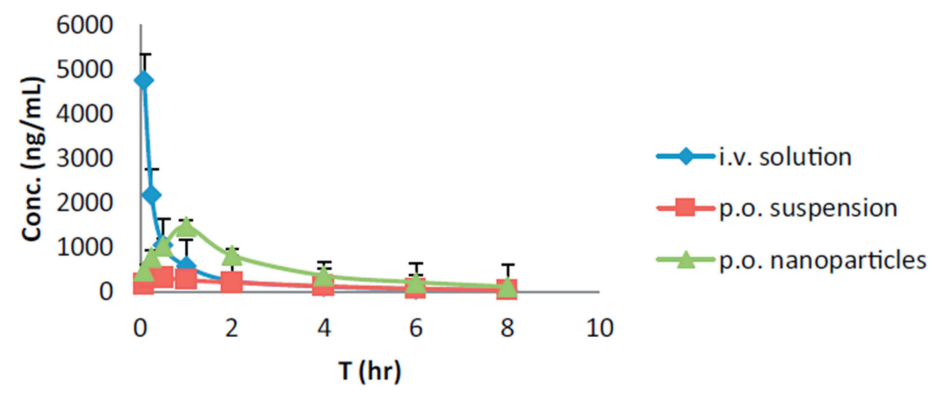

Figure I Example of Chitosan NPs preparation, Bay4I-4I09 loading, TEM characterization and delivery in in vivo model.

Notes: Reprinted from: Xue M, Hub S, Lu Y et al. Development of chitosan nanoparticles as drug delivery system for a prototype capsid inhibitor. International Journal of Pharmaceutics. 2015;495:77I-782.' Copyright (C) 2015 Elsevier B.V. All rights reserved. With permission from Elsevier.

Severe acute respiratory syndrome coronavirus-2 (SARS$\mathrm{CoV}-2$ ) spike glycoprotein (S protein) plays a key role in coronavirus pathogenesis, activating host immunological responses, and is a primary target for vaccine development. ${ }^{15-22}$ Based on the structure and properties of the coronavirus, targeted, high-efficiency, and low-toxic 

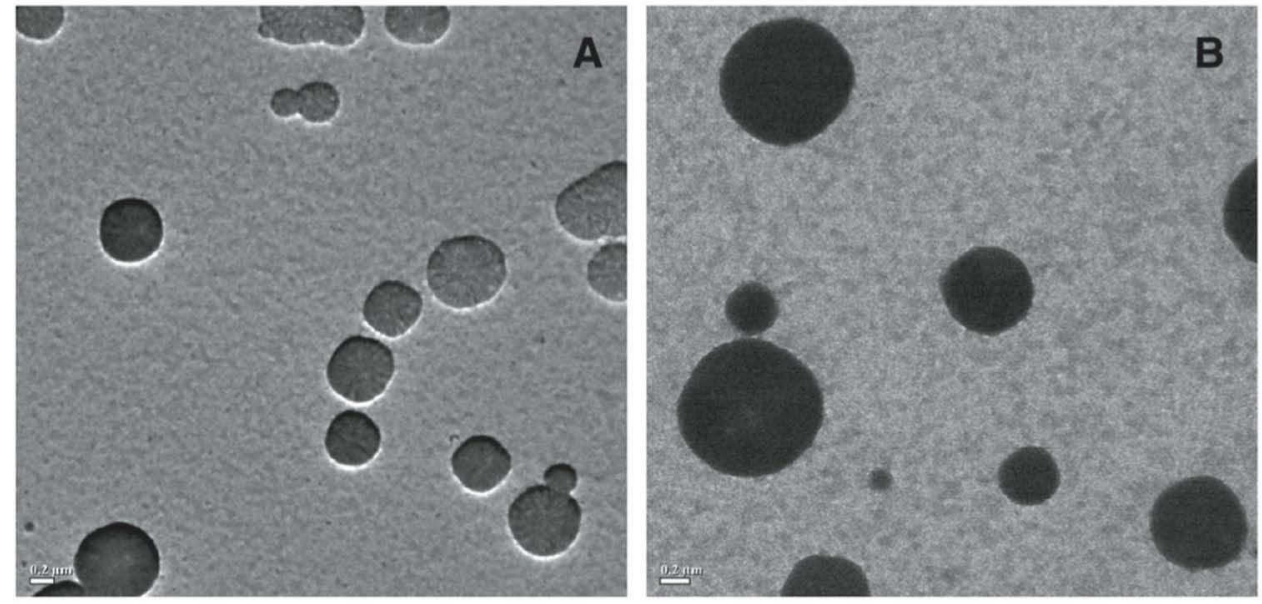

Figure 2 Transmission electron images of $(\mathbf{A})$ naked chitosan and $(\mathbf{B})$ saquinavir-loaded chitosan.

Notes: Reprinted from: Ramana LN, Sharma S, Sethuraman S, Ranga U, Krishnan UM. Evaluation of chitosan nanoformulations as potent anti-HIV therapeutic systems. Biochimica et Biophysica Acta. 20I4;I840(I):476-484. ${ }^{7}$ Copyright (C) 2014 Elsevier B.V. All rights reserved. With permission from Elsevier.

medications to treat the coronavirus are required. Chitosan NPs are one such candidate. Many studies have found that chitosan, along with other polysaccharides such as chitosan carrageenan, has potent antiviral properties. $^{23,24}$ Sulfated polysaccharides, for example, can obstruct virus entrance by inhibiting the pathogen surface receptors' positive charge, preventing them from attaching to heparan sulfate proteoglycan (HSPGs) on the host cell surface. ${ }^{25,26}$ Polysaccharides are thus appealing options for creating antiviral medicines. The antiviral properties, mechanisms, and possible uses of polysaccharide-based vaccine nanoparticles and drug delivery systems such as chitosan are discussed in this study, paving the way for a new approach to the development of medicines and vaccines for COVID19 treatment.

\section{Chitosan Nanoparticles for Drug Delivery}

Chitosan is a biocompatible natural polysaccharide that is cationic, highly basic, and mucoadhesive. It is frequently utilized in nano applications such as drug delivery. ${ }^{27-35}$ With the chitosan processing method, the nanoparticle design must carefully determine the required chemical and physical qualities of the chitosan, as well as the predicted biological environment (see Figures 3 and 4). According to our experience with chitosan, certain physical modifications are produced via blending, which entails the physical mixing of two or more substances in order to eventually obtain the appropriate NP size and morphological properties to make it ideal for use as a drug nano carrier (see Scheme 1). The quality and performance of the blend can be altered by adjusting the chitosan-to-addedingredients ratios. UV-Vis Spectroscopy, Zeta Potential, and Size Measurements of the produced NPs are then investigated using various techniques such as Transmission Electron Microscopy (TEM), Field Emission Scanning Electron Microscopy, Atomic Force Microscopy (AFM), Fourier-Transform Infrared Spectroscopy (FTIR), and X-Ray Particle Analysis (XPS). We were able to corroborate our understanding of the impacts of processing on bonding and flow properties using all these methods. ${ }^{8}$ Indeed, only few instances of chitosan NPs for antiviral drug delivery have been developed. The loading of Bay41-4109 (an antiviral medication) in chitosan nanoparticles ${ }^{9}$ produced by gelation of chitosan with tripolyphosphate (TPP) for treatment of Hepatitis B Virus (HBV) was recently developed and tested (as shown in Figure 1). Because of the strong interaction between polymer and medicines, efficient drug loading and capacity were achieved. Bay41-4109 was discovered dispersed in amorphous chitosan nanoparticles. The size of nanoparticles measured by TEM ranges between 150 and 200 nanometers. $^{27}$ Drug uptake was boosted due to an electrostatic interaction between the positive charge of the chitosan molecules and the negative charge of the cell membrane. In an in vivo study, ${ }^{9}$ chitosan nanoparticles were employed to sustain medication release due to their mucosa adhesion properties. The drug's circulation period in the blood stream was extended thanks to the nanoparticles (see Figure 1). The in vivo results showed that Bay414109 nanoparticles have a higher bioavailability, 

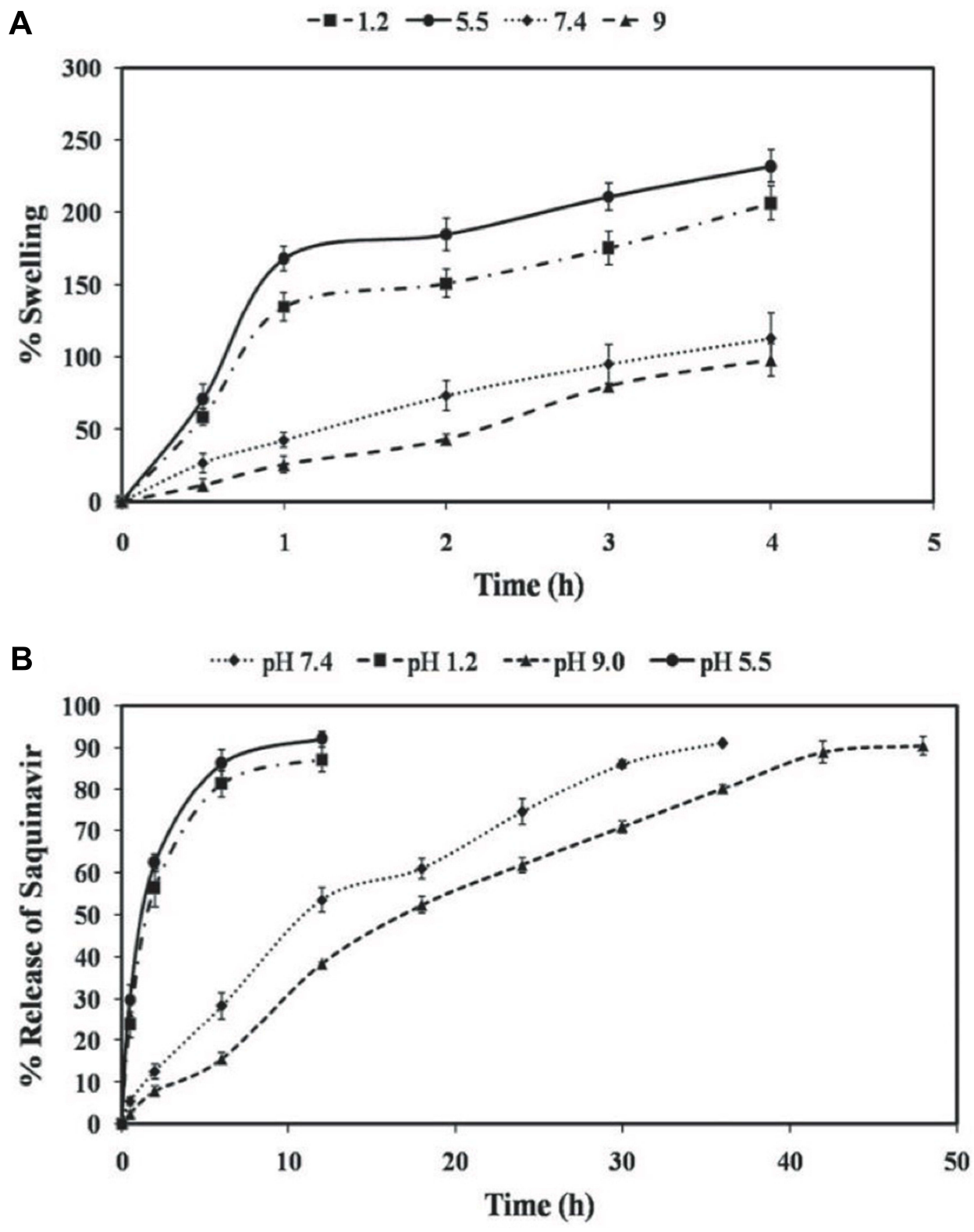

Figure 3 (A) Percentage swelling of chitosan and (B) in vitro release kinetics of saquinavir varying $\mathrm{pH}$ values.

Notes: Adapted from: Ramana LN, Sharma S, Sethuraman S, Ranga U, Krishnan UM. Evaluation of chitosan nanoformulations as potent anti-HIV therapeutic systems. Biochimica et Biophysica Acta. 2014;1840(I):476-484.7 Copyright (C) 2014 Elsevier B.V. All rights reserved. With permission from Elsevier.

indicating that oral delivery of Bay41-4109 for the treatment of $\mathrm{HBV}^{9}$ could be a viable option in the future.

In a recent paper, Ramana et $\mathrm{al}^{7}$ employed nanocarriers loaded with the antiretroviral medication saquinavir ${ }^{36}$ to overcome the limitations of antiretroviral therapy (ART), which is currently the most effective treatment for AIDS (as shown in Figure 2). Transmission electron microscopy and differential scanning calorimetry were used to examine the nanoparticles. The zeta potential, encapsulation efficiency, swelling characteristics, particle size properties, and encapsulation efficiency were all measured. They show a loading efficiency of $75 \%$ and a cell targeting efficiency of more than $92 \%$, as well as a swelling percentage of chitosan at various pH levels (see Figure 3). These findings revealed that a combination of diffusion and erosion $^{37}$ accounts for saquinavir release from the chitosan matrix. The rate of drug release is proportional to the amount of drug contained in the matrix, according to first order release kinetics. The erosion mechanisms are more prevalent at alkaline $\mathrm{pH}$, resulting in a progressive change in the surface area, according to the saquinavir release profiles. 
A Flow cytometry
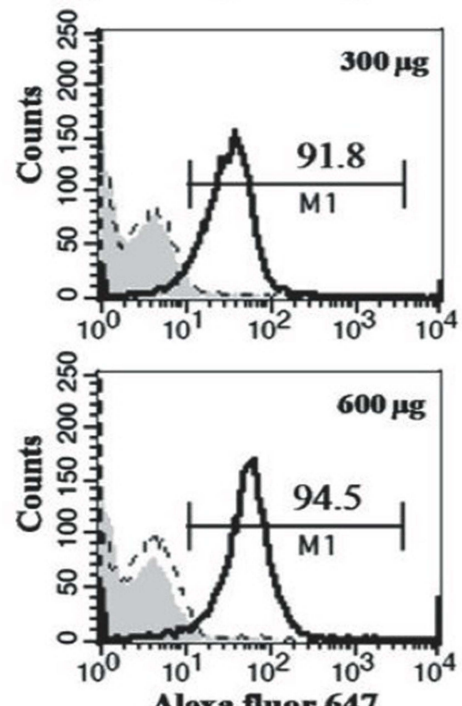

Alexa fluor 647
B Confocal Analysis

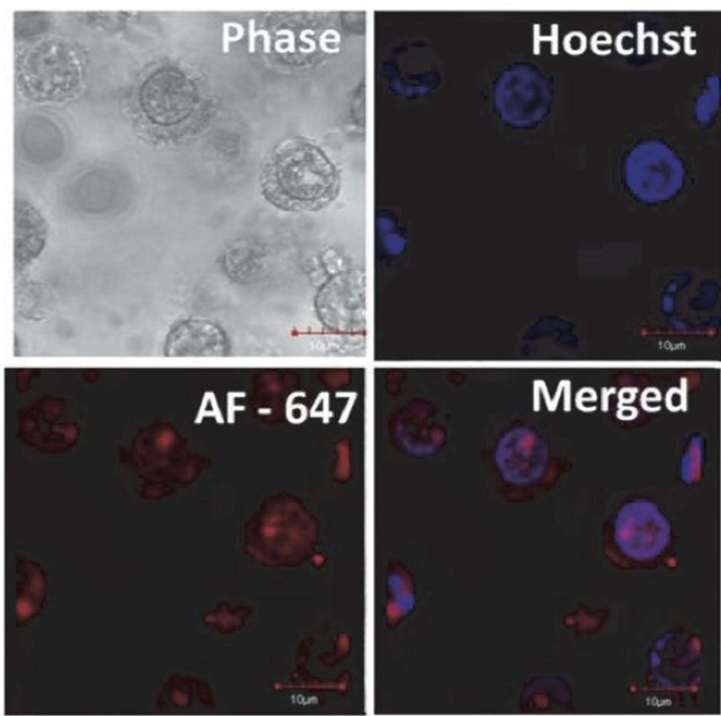

C

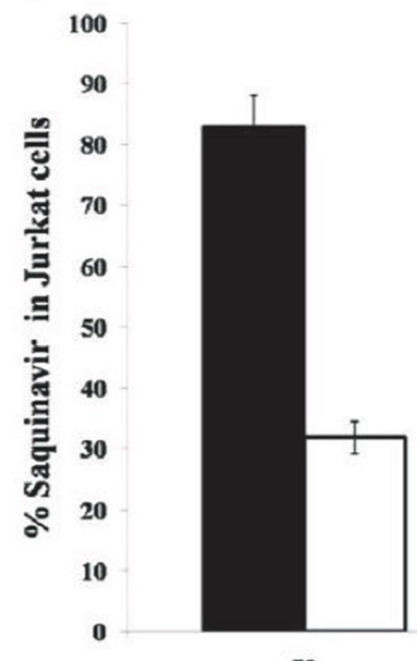

72

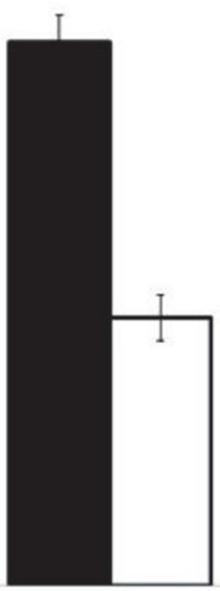

216 $\square \operatorname{sQv}_{\mathrm{NP}} \square \mathrm{sQv}$

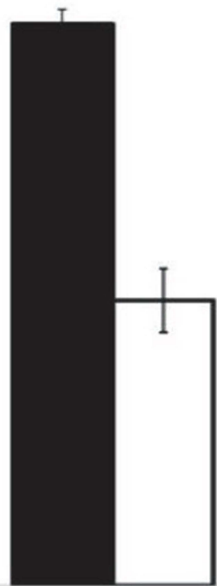

432

\section{Concentration $(\mu \mathrm{g} / \mathrm{mL})$}

Figure 4 Cell-targeting efficiency of the Alexa Fluor 647-loaded chitosan nanoparticles in Jurkat T-cells. (A) Flow cytometry. (B) Confocal images. (C) Cellular uptake of saquinavir loaded chitosan and plain saquinavir.

Notes: Adapted from: Ramana LN, Sharma S, Sethuraman S, Ranga U, Krishnan UM. Evaluation of chitosan nanoformulations as potent anti-HIV therapeutic systems. Biochimica et Biophysica Acta. 20I4;I840(I):476-484. ${ }^{7}$ Copyright (C) 2014 Elsevier B.V. All rights reserved. With permission from Elsevier.

Protein adsorption on the chitosan surface is inversely proportional to its zeta potential. ${ }^{7}$ As with the blank chitosan, a higher zeta potential encourages increased protein adsorption. Instead, because of modest surface charges, the drug-loaded chitosan has a lower zeta potential, which lowered protein adsorption. Confocal imaging and flow cytometry were used to examine the cellular absorption of chitosan nanoparticles coated with Alexa Fluor 647. The dye-loaded chitosan was uniformly distributed in the cytosol and nucleus of Jurkat cells, according to the confocal images. This demonstrated that chitosan nanoparticles successfully delivered the cargo to the desired cells (as shown in Figure 4).

Maximum swelling was measured at an acidic $\mathrm{pH}$, which coincided with maximum drug release. The drugloaded chitosan reduced serum protein adsorption slightly but had no effect on cellular absorption. Even at nanogram levels, the drug-loaded chitosan nanoparticles outperformed the free drug. Finally, the researchers found that chitosan nanoparticles loaded with saquinavir had a higher 


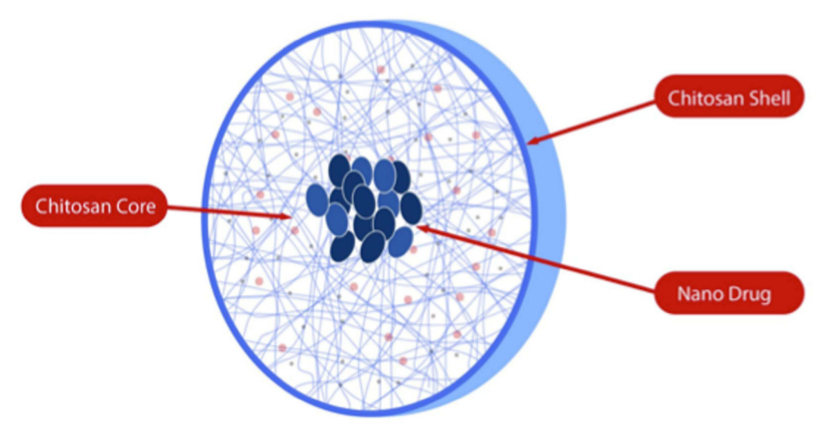

Scheme I Model of incorporation of nano-drug into chitosan.

drug loading potential and a higher cell targeting efficiency, resulting in effective viral proliferation suppression in target $\mathrm{T}$-cells. ${ }^{37}$ In the following paragraphs, major different types of viruses that are closely related to respiratory disease (such as different types of influenza viruses) will be discussed, and where the use of chitosan nanoparticles as antiviral nano-carriers or as new nano-vaccines could find fertile ground for growth.

\section{Viruses Type}

A complete review of the major types of viruses is provided in Figure 5. A, B, C, and D are the four kinds of influenza viruses. Almost every winter, human influenza
A and B viruses cause seasonal outbreaks of sickness (for example, the flu season) (Figure 5). The only influenza viruses that generate pandemics, or worldwide outbreaks of flu, are influenza A viruses. A pandemic can occur when a new and substantially distinct influenza A virus emerges that both infects people and spreads widely among them. Infections of influenza type $\mathrm{C}$ usually cause only mild disease and are not regarded to be the cause of human flu epidemics. Influenza D viruses are mostly found in cattle and do not infect or cause sickness in humans. The two proteins on the virus's surface, hemagglutinin $(\mathrm{H})$ and neuraminidase, are used to divide influenza A viruses into subtypes $(\mathrm{N})$. Only 131 subtypes have been found in nature, even though there are theoretically 198 distinct influenza A subtype combinations. A (H1N1) and A (H3N2) are two subtypes of influenza A viruses that are currently circulating in people (H3N2). Influenza A subtypes can be split into different genetic "groups" and "sub-groups" using nanoparticles. An influenza group (beyond subtypes or lineages) is a classification of influenza viruses based on the similarity of their HA gene sequences. The pandemic 2009 H1N1 virus, which appeared in the spring of 2009 and triggered a flu pandemic, is linked to the currently circulating "influenza" A (H1N1) viruses. This virus, dubbed "A (H1N1) pdm09
Influenza A

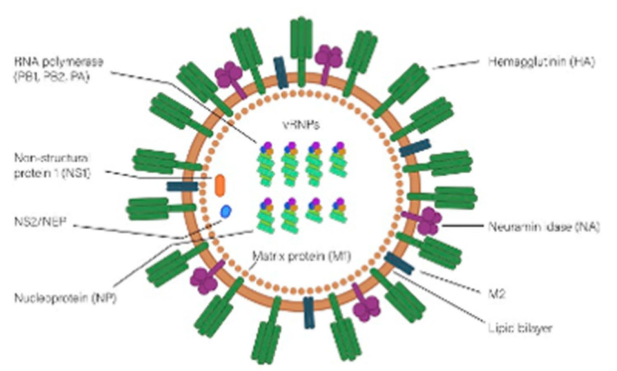

H3N2

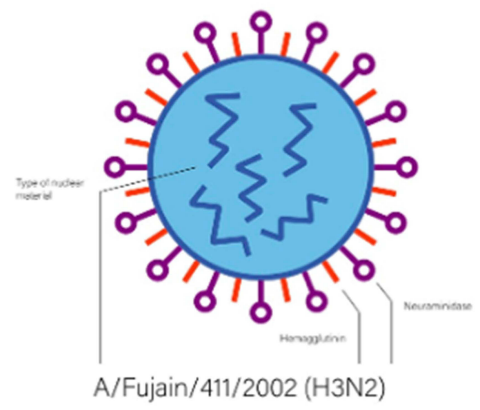

Influenza Types

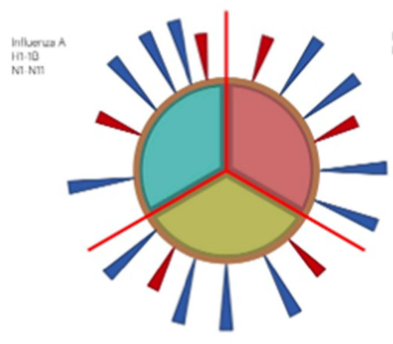

nereses

$\mathrm{H} 1 \mathrm{~N} 2$

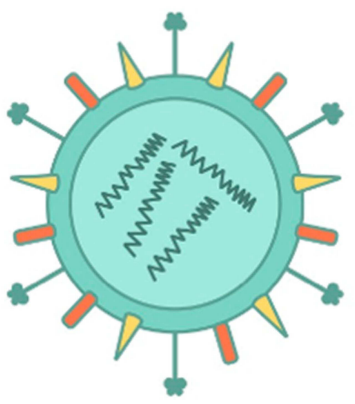

$\mathrm{H} 1 \mathrm{~N} 1$
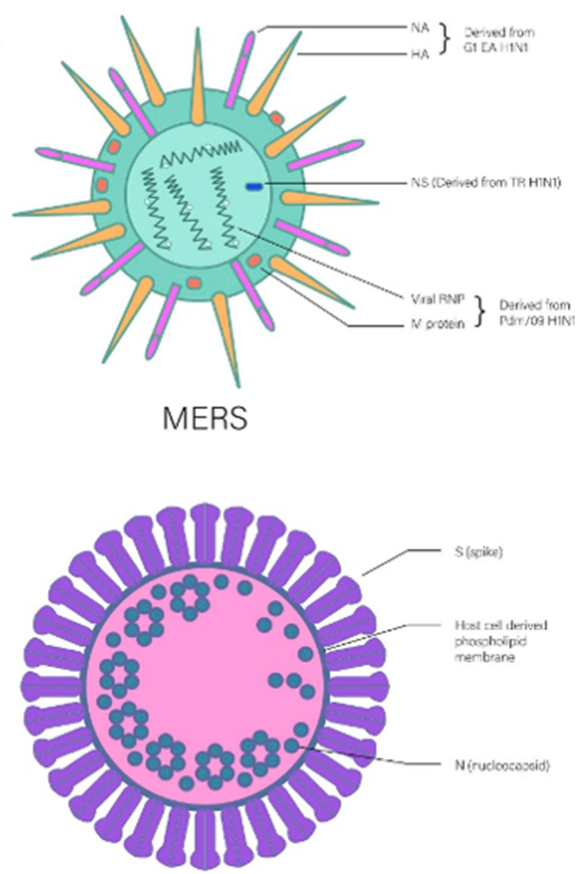

Figure 5 Overview of different types of viruses related to COVID-19. 
virus" and more often known as "2009 H1N1," has continued to circulate. Over time, these H1N1 viruses have showed very minor genetic alterations as well as changes in their antigenic features (ie, the virus's properties that effect immunity). (Source: CDC's 2009 H1N1 Flu webpage, https://www.cdc.gov/flu/about/viruses/types.htm).

Influenza $\mathrm{A}(\mathrm{H} 3 \mathrm{~N} 2)$ viruses, out of all the influenza viruses that often circulate and cause illness in people, tend to evolve faster, both genetically and antigenically. In recent years, influenza $\mathrm{A}(\mathrm{H} 3 \mathrm{~N} 2)$ viruses have split into various clades that continue to circulate. $\mathrm{B} /$ Yamagata and $B /$ Victoria are the two lineages of influenza $B$ viruses. Influenza B viruses, particularly influenza A(H3N2) viruses, change more slowly than influenza $A$ viruses. MERS is a viral respiratory disease caused by a novel coronavirus (Middle East respiratory syndrome coronavirus, or MERS-CoV), which was initially discovered in Saudi Arabia in 2012. Fever, cough, and shortness of breath are common MERS symptoms. There have also been reports of gastrointestinal issues, such as diarrhea. Approximately $35 \%$ of MERS-CoV patients that have been reported have died. Even though the majority of human MERS-CoV infections have been linked to humanto-human infections in health care settings, the scientific community now believes that dromedary camels are a key reservoir host for MERS-CoV and an animal source of MERS infection in people. Despite this, their specific involvement in virus transmission and the route(s) of transmission remain unknown. Severe disease can cause respiratory failure, necessitating the use of mechanical ventilator and intensive care unit treatment. Older persons, people with compromised immune systems, and people with chronic conditions like kidney disease, cancer, chronic lung disease, and diabetes appear to be more susceptible to the virus. (https://www.who.int/newsroom/fact-sheets/detail/middle-east-respiratory-syndromecoronavirus-(mers-cov)) Unless there is intimate contact, such as while providing unprotected care to a patient, the virus does not easily spread from person to person. MERS$\mathrm{CoV}$ is a zoonotic virus, which means it can spread from person to person. This means that it is passed down from one generation to the next. Humans are infected by direct or indirect contact with diseased dromedary camels, according to studies. MERS-CoV has been found in dromedaries in various Middle Eastern, African, and South Asian nations. Ebola virus disease (EVD), often known as Ebola hemorrhagic fever, is an uncommon but serious and often fatal infection that affects people. The virus spreads from wild animals to humans. The typical case fatality rate for EVD is roughly $50 \%$. In previous epidemics, case mortality rates ranged from $25 \%$ to $90 \%$. Ebola vaccines are currently being developed and have been used to halt the development of Ebola epidemics in Guinea and the Democratic Republic of Congo (DRC). (WHO web page, https://www.who.int/news-room/fact-sheets/detail/ebolavirus-disease). SARS-associated coronavirus causes a viral respiratory ailment known as severe acute respiratory syndrome (SARS) (SARS-CoV). In February 2003, SARS was discovered for the first time in Asia. Before the SARS global pandemic of 2003 was contained, the virus had spread to more than a dozen nations in North America, South America, Europe, and Asia. (Globe Health Organization web page, https://www.who.int/news-room /fact-sheets/detail/middle-east-respiratory-syndromecoronavirus-(mers-cov)) Since 2004, no known cases of SARS have been reported anywhere in the world.

\section{COVID-I 9 (SARS-COV-2 Disease)}

It is not unusual to see the viral epidemic in the world affecting animals and human beings. The world is witnessing and hearing probably the only name from all over the apparent world corona viruses. However, many people are not even aware that this is not the first time that humankind has been affected by this virus group. Influenza is also caused by a coronavirus. This outbreak is one of major attempt by coronavirus family members to demonstrate harmful effects on humanity. A new coronavirus is the source of respiratory disease. COVID-19 is a virus of the beta-coronavirus family (see Figure 6). It was given the moniker SARS-CoV-2 because of its genetic and structural resemblance to SARS-CoV-1. Because of its rapid global spread, the WHO declared SARS-CoV-2 a pandemic on March 11, 2020. The ongoing rise in both cases and deaths since August 2020 needs the development of an effective SARS-CoV-2 vaccine as soon as possible. At the time of writing there were more than 200 million people have become affected and 4 million people have died worldwide. Face masking, social separation, and clean hands have been the sole methods utilized to safeguard people until recently. This may help to inhibit the virus's transmission. The world has preferred to lockdown the daily routine and considered "Lockdown" as the only option available to fight the disease. The discovery of a proper vaccination, allowing a return to normal human social interaction, is the only way to eradicate it globally. For this reason, many efforts performed by the whole scientific community together with big Pharma have 


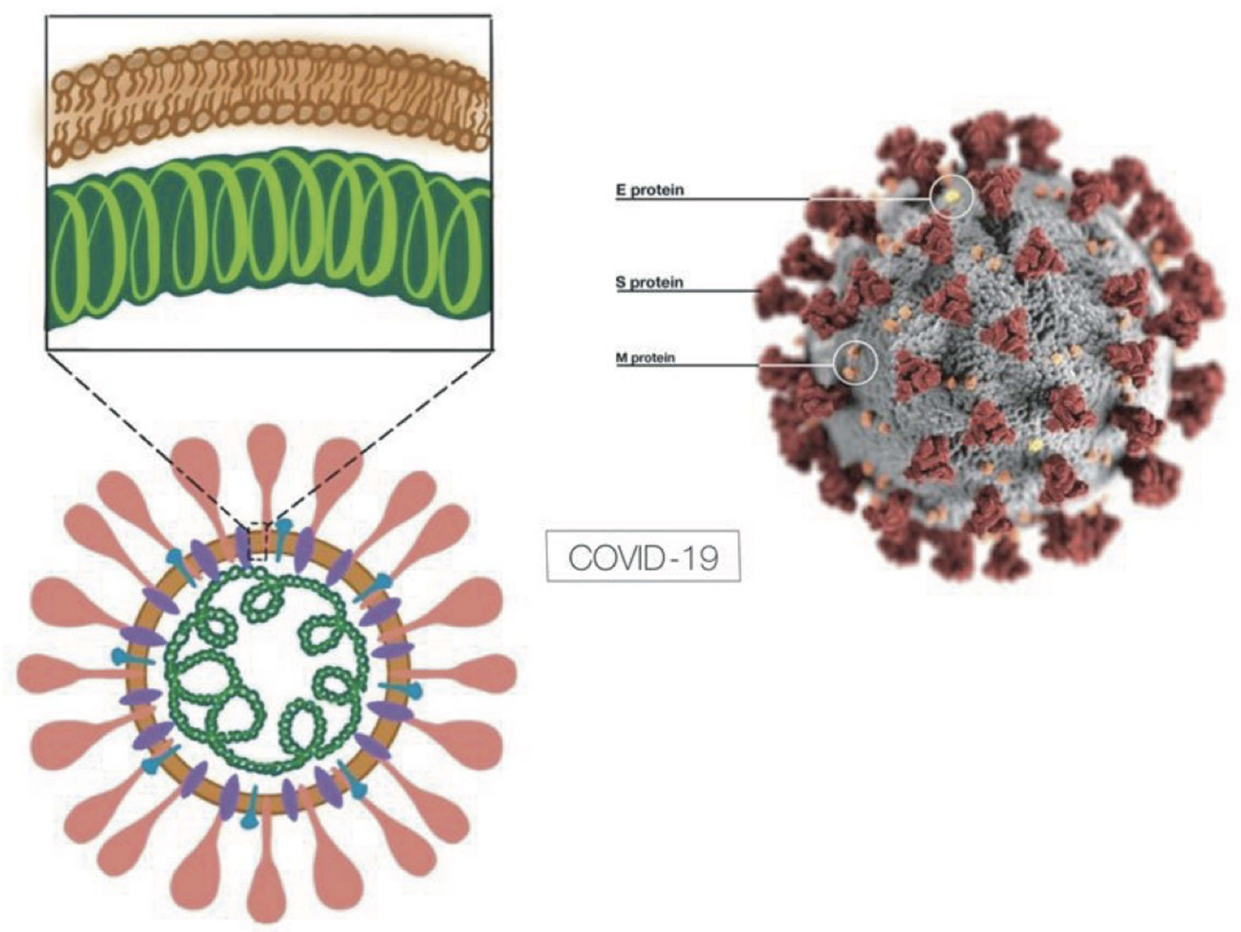

Figure 6 Structure of COVID-19 depicted surface proteins (NB the spikes in the outer surface of the virus are viewed by electron microscopy). The protein particles E, S, and $\mathrm{M}$, located on the outer surface of the particle, have all been labeled as well.

Notes: The image on the left is reproduced from: Huang H, Fan C, Li M, et al. COVID-19: A Call for Physical Scientists and Engineers. ACS Nano. 2020 ; I4(4):3747-3754. doi: $10.1021 /$ acsnano.0c02618. ${ }^{74}$ Copyright (C) 2020 American Chemical Society. The image on the right was created by the Centers for Disease Control and Prevention (CDC). Credit: Eckert A, Higgins D. Available from: https://phil.cdc.gov/Details.aspx?.pid=233।3. Accessed November 23, 202I. ${ }^{75}$

been done to understand diseases mechanisms and to quickly develop a number of vaccines by using either new (but with several years of experience in the struggling of tumors) technologies (such as messenger RNA (mRNA)type) or old but well efficient technology (eg Adenovirus (AD)-type). In the next paragraphs these new vaccines and their mechanism of action will be overviewed.

\section{Vaccination and Development of Vaccines Anti-COVID-19}

The current level of vaccine development against SARS$\mathrm{CoV}-2$ coronavirus is reviewed in this study, with a focus on newly published data, and is currently in use in various nations throughout the world. Various vaccine regimens against SARS-CoV-2 have been shown to be safe and immunogenically efficient (Figure 7). The open reading frames (ORFs), as shown in Figure 7, with the four nomenclature systems used to identify each ORF. These ORFs code for proteins that can be used to generate vaccines and drugs. The spike (S) glycoprotein, which protrudes from the virion's surface, drives $\mathrm{CoV}$ into target cells via receptor- mediated endocytosis. The $\mathrm{S}$ protein is a significant viral attachment protein that is required for virus binding and envelope fusion, making it a prime target antigen for vaccine development. An inactivated or whole-killed virus (WKV) vaccine, a live-attenuated SARS-CoV vaccine, a viral vector such as Adenovirus (AD) or vaccinia virus carrying SARS-CoV genes, bacterial vectors, recombinant SARS-CoV proteins, or DNA vaccines were all tested for SARS-CoV vaccination. Animals have been effectively vaccinated against $\mathrm{CoVs}$ using live-attenuated $\mathrm{CoV}$, killed $\mathrm{CoV}$, DNA vaccines, and viral vectored vaccines, which has now led to a viable human vaccine.

\section{The Sputnik Vaccine's Mechanism of Action}

Sputnik V was the world's first COVID vaccination to be approved. The spike proteins' protein coding genes are inserted into two human Adenovirus vectors. Vectors are viruses that have been genetically altered to prevent them from replicating. They are not harmful to the body. It is impossible to become infected since vectors only 


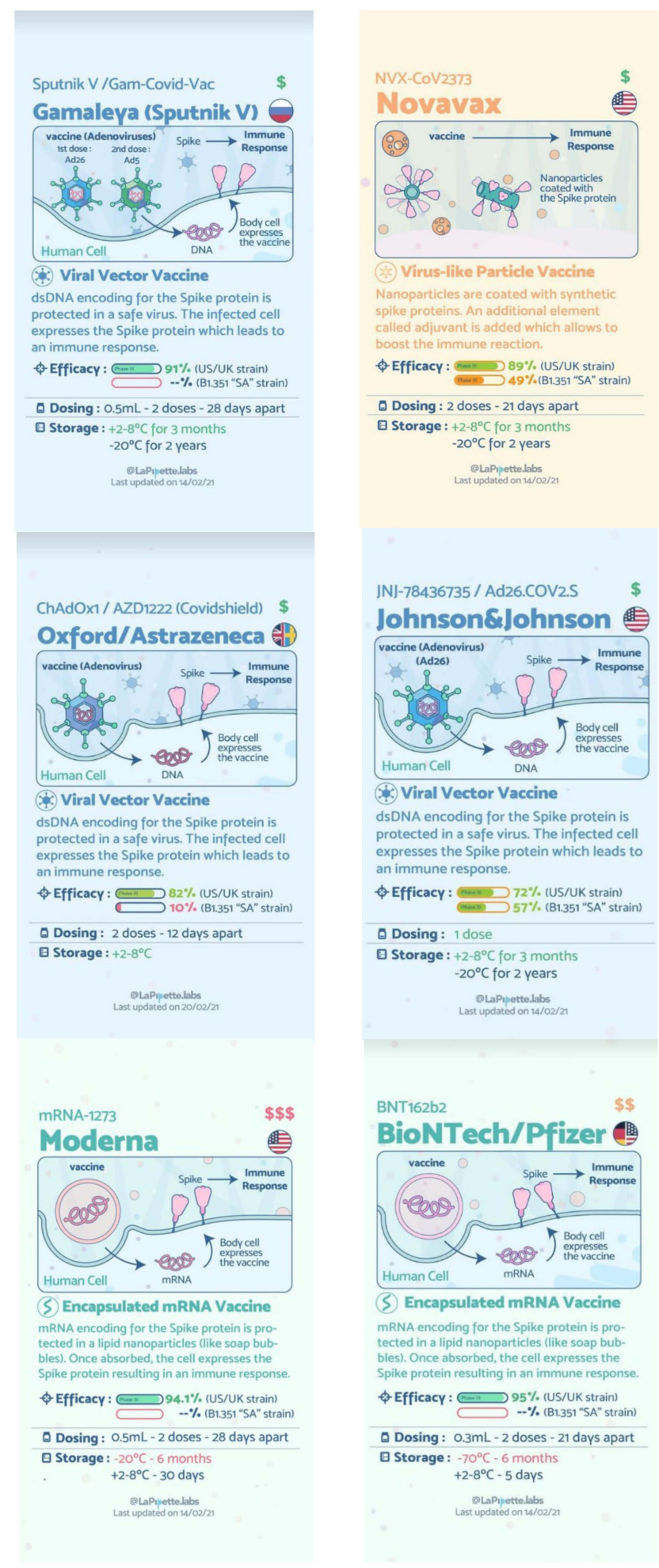

Figure 7 Basic data of the types, mechanism, and examples of vaccines in use against SARS-CoV-2 and countries of origin.

Notes: Reproduced from Lapipette.Labs. COVID-19 vaccine cards; English VI; 202I. Available from: https://lapipette.com/vaccine_cards. Accessed November 25, 202I. ${ }^{76}$ Creative Commons Attribution-NonCommercial-No Derivatives 4.0 International License (https://creativecommons.org/licenses/by-nc-nd/4.0/legalcode). 
carry protein coding genes from the Spike corona virus. During the initial immunization, an AD-based vaccine ${ }^{15}$ enters the cell and the immune system begins to grow. After 21 days, the second vector AD5 immunization is given. It improves the immune system's reaction. The corona virus exploits receptor binding domains (RBDs) of Spike proteins to engage receptors before breaching the cellular membrane. Sputnik makes advantage of a gene that codes for Spike proteins, which are used by the virus to enter human cells. The Spike protons gene is derived from the corona virus and placed into a vector: a virus that has been attenuated to prevent it from growing inside the human body after injection. Adenoviruses, which cause the common cold, are used in Sputnik 5. To increase the vaccine's effectiveness, two distinct Adenoviruses, RAD26 and RAD5, are used for the first and second doses. The genes that produce infection in these Adenoviruses are ejected, while the gene that codes for Spike proteins is introduced. Adenoviruses are widely used as vectors because they are simple to create. The modified viruses are designed to simulate a true corona virus infection and teach the immune system to recognize Covid-19. Despite the fact that the modified virus does not cause infection, it should nonetheless cause the body to create antibodies to neutralize the corona virus. The Gamaleya Research Institute of Epidemiology and Microbiology in Moscow created the vaccination. With $0.5 \mathrm{~mL}$ doses 28 days apart, Sputnik effectiveness was reported to be $91 \%{ }^{15}$

\section{The Novavax Vaccine's Mechanism of Action}

The coronavirus vaccine NVX-CoV2373 from Novavax uses recombinant nanoparticle technology and Novavax's Matrix$\mathrm{M}$ adjuvant to elicit an immunological response and high levels of neutralizing antibodies. Novavax picked the gene for the spike protein from the coronavirus genomic sequence and generated a modified version. The genes were then cloned into an insect-infecting baculovirus. They next infected moth cells with the virus, especially cells from the fall armyworm insect, causing them to manufacture coronavirus spike protein. The spike protein was created by the vaccination. People are then administered the spike, and their immune responses are primarily focused on the spike. The vaccination is safe to keep in regular refrigerators. Novavax effectiveness was determined to be $99 \%$ after two doses separated by 21 days. ${ }^{16}$

\section{The Oxford/AstraZeneca Vaccine's Mechanism of Action}

Vaccines function by exposing the immune system to pathogen antigens that cause disease in humans, such as viruses. After that, the immune system builds a defense. $B$ cells and $T$ cells are immune cells that produce antibodies to kill infections. Antigen memory is conserved in some $\mathrm{B}$ and $\mathrm{T}$ lymphocytes. These long-lasting memory cells can immediately order new antibodies to destroy the pathogen and assault infected cells if the person is exposed to the infection at some point.

In effect, the principle of vaccination is to "duplicate" an infection, but in a "saved" way, in order to create immunity without causing illness. The person who has been vaccinated will be protected within a few weeks once $\mathrm{T}$ cells and $\mathrm{B}$ cells have been created. Certain vaccines require two doses since the first dosage alone may not provide complete immunity in some persons. Many people can increase their protection by taking multiple doses.

Different ways are employed to present the virus's antigens to the immune system in the case of coronavirus vaccines. Some of them, such as the Sinopharm and Sinovac vaccines in China, simply inject the coronavirus into the body intact and inactivated. Others, on the other hand, "teach" the vaccinated person's cells to create a specific portion of the coronavirus: the spike protein on the virus's outer surface, which is immediately identifiable as antigen.

These vaccines accomplish this by transferring a portion of the coronavirus's genetic code encoding the spike protein to the body's cells, which then read the code and begin producing the protein. Other vaccines, such as those developed by Pfizer/BioNTech and Moderna, deliver the code in the form of messenger RNA (mRNA). Others utilize a harmless virus to get the genetic code into cells; the Oxford vaccine uses ChAdOx1, a chimpanzee adenovirus that has been genetically changed to be unable to replicate. Virus-vector vaccines are what they are called. The effectiveness of Oxford/AstraZeneca was determined to be $85 \%$ after two doses given 12 days apart. ${ }^{18,20}$

\section{The Johnson\&Johnson Vaccine's Mechanism of Action}

The Janssen vaccine (also known as Johnson\&Johnson) is a viral vector vaccination. It's a type of adenovirus that causes mild cold or flu symptoms in humans. This virus 
has been engineered by Johnson\&Johnson to contain DNA that codes for the SARS-CoV-2 virus's spike protein. One of the virus's identifying properties for immune cells that infiltrate human cells is the spike protein. The virus then injects the spike protein's genetic material into our cells and reads that DNA to build copies of the spike protein, which triggers an immune response (this function is similar to a mRNA vaccine, except the process of making the spike protein starts at the DNA versus the mRNA stage in protein translation). Johnson\&Johnson's method transports DNA coding for the SARS-CoV-2 spike protein via a chimpanzee adenovirus. It only uses one dosage. Single dosage efficacy was determined to be $72 \%{ }^{19}$

\section{The Moderna Vaccine's Mechanism of Action}

A mRNA vaccine is the Moderna vaccination. This vaccination operates in a unique way compared to other vaccines. mRNA vaccines transfer the genetic code to our cells, causing them to produce a protein that triggers the immune system's reaction. The body creates antibodies and develops long-term immunity as a result. Efficacy was reported to be $94.1 \%$ after two doses separated by 28 days. The Moderna vaccine operates in the same way that the BioNTech/Pfizer vaccine does. Because it is an mRNA vaccine, this mRNA wrapped in a lipid bilayer shell is injected into the body, where it merges with certain cells and is released into the cytoplasm rather than the nucleus. While in the cytoplasm, it can interact with ribosomes, causing mRNA to be broken into pieces. And antibodies will create further immunogenic responses, such as a $\mathrm{T}$ cell response, in reaction to these immunogenic proteins. The effectiveness of the Moderna vaccination is $94.1 \%$ when given in two doses 28 days apart. ${ }^{20,21}$

\section{The BioNTech/Pfizer Vaccine's Mechanism of Action}

The RNA is contained within the virus, which is surrounded by Spike proteins. The virus can connect to the host cell thanks to the Spike proteins. The "S gene" in RNA is responsible for Spike protein synthesis. The vaccine comprises mRNA that is wrapped in a solid lipid nanoparticle with a message (see Figure 7). Solid lipid nanoparticles will merge with the human cell membrane when the vaccine is administered into the human muscle, allowing the mRNA to reach the cells. This will reach the host cell's ribosome, where the cell will produce a protein similar to Spike proteins. Some Spike proteins make it to the cell surface. Class 1 of the MHC. Our cell will be attached by a cytotoxic $\mathrm{T}$ cell. Other Spike proteins are transported to other cells, such as Plasma cells. After that, plasma cells produce antibodies against Spike proteins, which act as a strong defense against any Covid -19 that attacks the same cell. 95\% efficacy was established when two doses of $0.3 \mathrm{~mL}$ were given 21 days apart. $^{22}$

\section{Other Vaccines Used in China and} Several Other Countries Include The Sinopharm Vaccine's Mechanism of Action (Inactivated Vaccine)

The corona virus ${ }^{38}$ will be injected into Monkey kidney cells to serve as host cells, allowing the virus to grow. $\beta$ propiolactone (BPL), which inactivates the virus's genetic material. The vaccination is created from this.

\section{BioNTech/Pfizer Vaccine Contains Solid Nano Lipids}

Solid lipid nanoparticles (SLNPs) were first developed in 1991 with the goal of providing biocompatibility, storage stability, and the prevention of drug degradation. ${ }^{39}$ SLNPs are nanoscopic colloidal carriers $(50-1000 \mathrm{~nm})$ that have been created to address the flaws of conventional colloidal carriers (eg, polymer degradation and cytotoxicity, lack of a suitable large scale production method, inferior stability, drug leakage and fusion, phospholipid degradation, high production $\operatorname{cost}^{39}$ ). When compared to typical colloidal carriers, SLNs have numerous advantages, including reduced toxicity, a high surface area, delayed drug release, greater cellular absorption, and the capacity to improve drug solubility and bioavailability. ${ }^{39,40}$ This is what Pfizer BioNTech used in their most recent creation of a Nano type vaccine. The drug release from SLNs is determined by the matrix type and the drug's placement in the formulation. SLNs made from biodegradable and biocompatible materials can include both hydrophilic and lipophilic bioactive, making them a feasible choice for controlled and targeted drug delivery. ${ }^{40}$ The drug is usually disseminated or dissolved in the solid core of SLNs, which is hydrophobic with a monolayer coating of phospholipids (see Scheme 2). ${ }^{39,40}$

SLNPs are nano-vectors developed to replace liposomes, lipid emulsions, and polymeric nanoparticles as colloidal drug delivery vehicles. SLNPs offer a chance to develop novel therapeutic prototypes for drug delivery and 


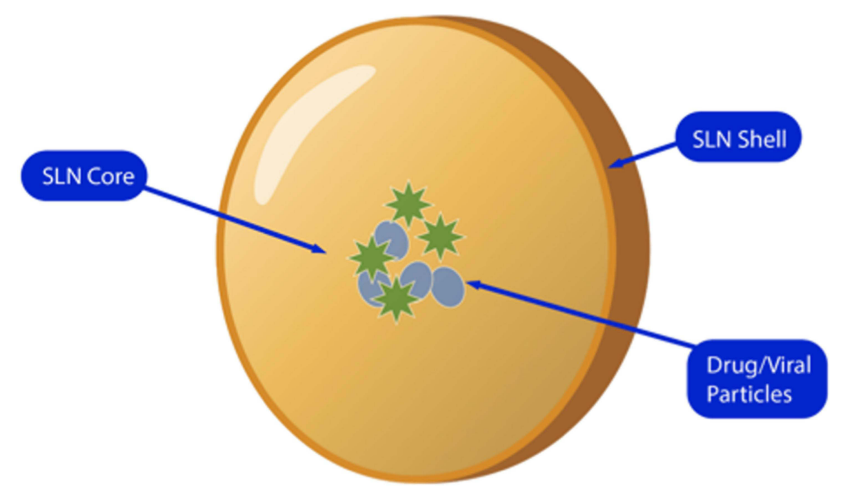

Scheme 2 Solid lipid nanoparticle with drug/viral particles-enriched shell: model of incorporation of active compounds into SLNPs.

targeting, because of their unique size dependent features and capacity to load medicines. Many academics throughout the world are interested in SLNPs because they have a lot of potential for achieving the objective of targeted and regulated medication delivery.

\section{Covid-1 9 Antiviral Drugs}

Because there are currently no licensed antiviral medications that successfully target SARS-CoV, vaccination is the most likely method of avoiding SARS in people around the world, particularly those who are most at risk (eg healthcare workers). A successful SARS vaccine might be used to protect healthcare workers, laboratory employees, and other at-risk people as a preventative measure. However, various trials for SARS-CoV medication research are now underway; such examples are listed and overviewed below (see also Figure 8 for their chemical structures).

\section{Hydroquinone (HQ)}

Chloroquine (see below) and hydroquinone are considered promising treatment targets against the recently found COVID-19, according to increasing research. Chloroquine has been used as an anti-malarial and antiautoimmune illness medicine for decades. The mechanism of action of chloroquine and hydroquinone against virus infection, on the other hand, is still unknown. Recent research suggests that both medications are engaged in numerous pathways that protect against viral infections (SARS-CoV). ${ }^{41,42} \mathrm{~A}$ recent study on chloroquine and hydroxyquinone found that both medications efficiently reduced SARS-CoV-2 glycosylation and functioned as potent inhibitors at both entry and post-entry stages of the recently emerging coronavirus (COVID-19) on
VeroE6 cell line. In an in vitro research, their combination increased suppression of COVID-19 on the VeroE6 cell line $^{36}$ at a low dosage concentration.

\section{Remdesivir (RDV)}

Given the increasing epidemic and the urgent need for effective medicines, existing antiviral drugs may be a better option than creating and testing wholly new pharmacological regimens, which would take more time. Remdesivir, an analog that works by prematurely inhibiting viral RNA replication after it has been integrated into RNA chains, ${ }^{44}$ could be useful in the real outbreak. The medicine had previously failed an Ebola virus trial, ${ }^{45}$ but Wuhan researchers have demonstrated its efficacy in non-human primate and human cell lines infected with the SARS-2 virus. ${ }^{43}$ Three patients in a case series of 12 COVID-19 patients in the United States reported that the medicine was well-tolerated, with little side effects, however one patient did experience rectal bleeding. ${ }^{46}$ Several ongoing trials are currently investigating the drug's use in COVID-19 patients. ${ }^{47,48}$ Patients who require supplementary oxygen (AI) and/or are on mechanical ventilation or extracorporeal membrane oxygenation should take RDV (ECMO). The FDA has not yet authorized the drug. ${ }^{49}$ Adults hospitalized with Covid-19 were treated with intravenous RDV in a recent double-blind, randomized, placebo-controlled research, which revealed lower respiratory tract involvement. Patients who received RDV recovered in 11 days on average, compared to 15 days for those who received a placebo. ${ }^{50}$

\section{Chloroquine (CQ) and Hydroxychloroquine (HCQ)}

Chloroquine (CQ) and hydroxychloroquine (HCQ) are two types of chloroquine (HCQ). Chloroquine, an anti-malarial and immunosuppressive medicine commonly used in the treatment of rheumatoid arthritis, ${ }^{42}$ was another substance tested by the Wuhan researchers. Chloroquine works through two different mechanisms: For starters, it raises endosomal $\mathrm{pH}$, which inhibits the activity of enzymes that are required for proteolytic processing and viral replication. ${ }^{51,52}$ Due to the potential of cardiac issues, the FDA has revoked the emergency use authorization (EUA) for hydroxychloroquine and chloroquine for COVID-19 outside of a hospital setting or a clinical trial. This conclusion was based on recent findings from a major, randomized clinical trial in hospitalized patients, which revealed that these drugs had no advantage in reducing the risk of mortality or expediting recovery. 


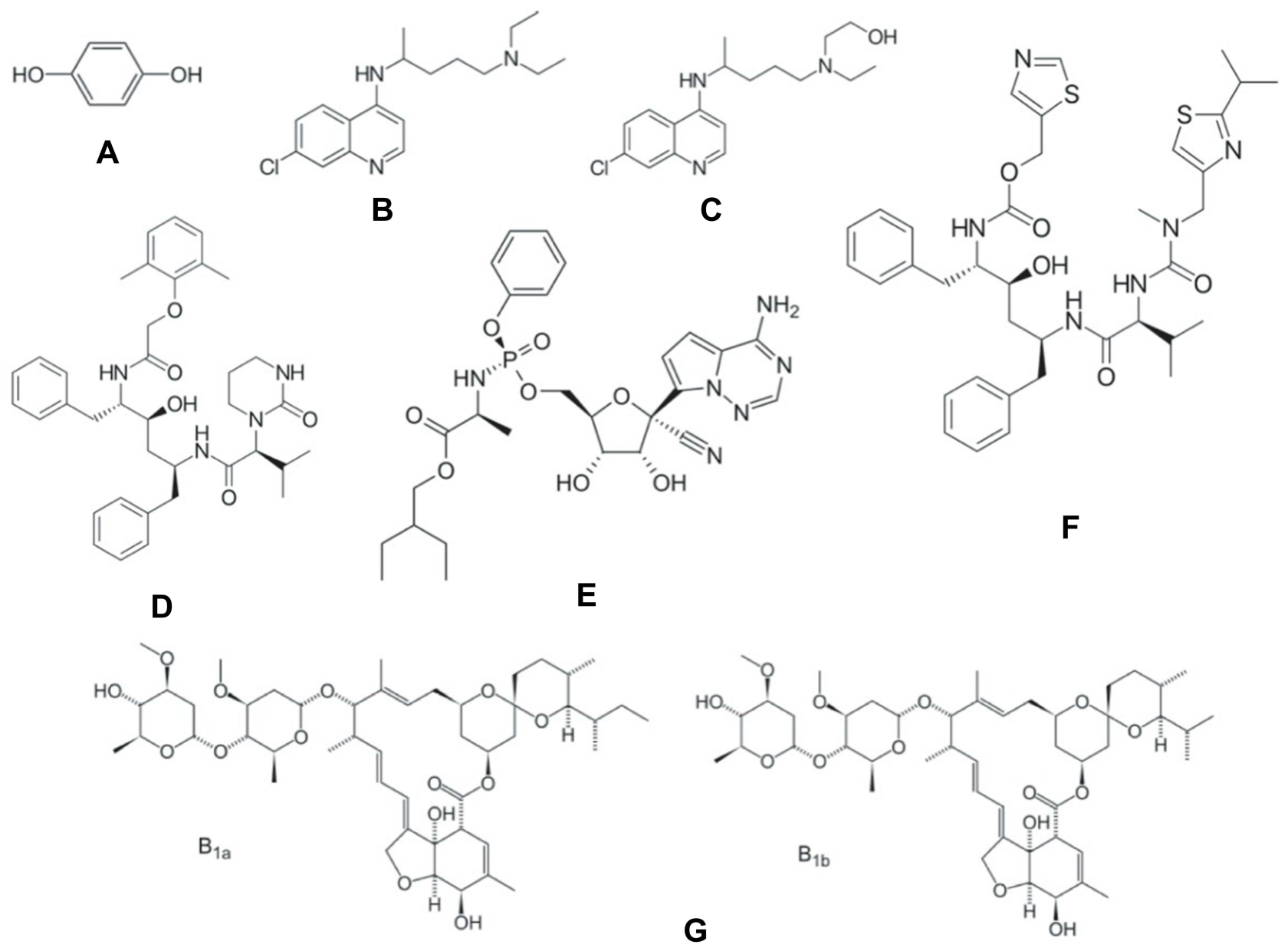

Figure 8 Antivirals chemical structures. (A) Hydroquinone, (B) chloroquine, (C) hydroxychloroquine, (D) lopinavir, (E) remdesivir, (F) ritonavir, (G) ivermectin.

\section{Lopinavir (LO)/Ritonavir (RI) ${ }^{53}$}

In vitro and animal investigations, lopinavir (LPV) and ritonavir combination (LPV/r) therapy have been examined for prior coronavirus epidemics, with varying degrees of success ${ }^{54}$ either alone or in combination with other medications such as ribavirin and interferon. Both medications are proteinase inhibitors, with ritonavir boosting the availability of LPV by blocking the enzyme CYP3A4. ${ }^{55,56} \mathrm{LPV} / \mathrm{r}$ usage was associated with lower rates of mortality, intubation, acute respiratory distress syndrome (ARDS), lowered viral loads, and less frequent need for steroids during the SARS pandemic, according to two retrospective studies,${ }^{57-59}$ however, it was not more helpful than pulsed steroids when used as rescue therapy. COVID-19 research has proved less promising, with a retrospective study finding no statistically significant differences in viral conversion rates when LPV/ r50 was used. A recent study found that treating individuals with severe COVID-19 with lopinavir-ritonavir did not provide any additional benefit over usual care.

\section{Ivermectin}

Ivermectin was first discovered as an inhibitor of the interaction between the human immunodeficiency virus-1 (HIV-1) integrase protein (IN) and the importin (IMP)/1 heterodimer responsible for IN nuclear import. ${ }^{59}$ Since then, it has been shown to inhibit IN nuclear import as well as HIV-1 replication. ${ }^{60}$ Ivermectin, an FDA-approved anti-parasitic drug that has previously been shown to have broad-spectrum anti-viral activity in vitro, is an inhibitor of the causative virus (SARS-CoV-2), with a single addition to Vero-h SLAM cells 2 hours after infection with SARS-CoV-2 resulting in a 5000fold reduction in viral RNA at 48 hours. ${ }^{61}$ To test the efficacy of ivermectin, cells infected with SARS-CoV-2 were given repeated dilutions of the drug 2 hours after infection, and the supernatant and cell pellets were collected for real-time RTPCR 48 hours later. ${ }^{61}$ As previously stated, supernatant and cell pellets from samples treated with $5 \mathrm{M}$ ivermectin at 48 $\mathrm{h}$ showed a $>5000$ reduction in viral RNA, resulting in a $99.98 \%$ reduction in viral RNA in these samples. 
Furthermore, at any of the amounts studied, ivermectin showed no harm. Under these conditions, the IC50 of ivermectin therapy was calculated to be $2 \mathrm{M}^{61}$

\section{Discussion}

Many recent studies have shown the efficiency of various nanoparticles as nano-tools for the treatment of serious disorders including cancer. ${ }^{62-64}$ Only a few groups, however, have been actively used for antiviral therapeutic targeting. ${ }^{7,9}$ Based on our previous work on Conjugation of EGCG and Chitosan NPs, ${ }^{8}$ a reasonable hypothesis would be to investigate the features and advantages of chitosan as a nano-carrier for antiviral drug delivery in the fight against recent (like COVID 19) and future coronaviruses. Very recently Safarzadeh et $\mathrm{al}^{35}$ in a review article just published, have shown the potential applicability of chitin and chitosan to fight this overwhelming viral pandemic by overviewing the potential application of these materials in terms of their direct antiviral activities, the immune system associated effects and also as vehicles for targeted delivery of antiviral drugs. ${ }^{35}$

Poor water solubility and intrinsic dissolving rate are the key difficulties influencing oral distribution of many existing drugs, such as antivirals for HIV4 (eg, mass of the drug dissolved per time unit and area). Targeting coronaviruses such as COVID-19 is likely to provide comparable difficulties. As a result, the chitosan-based nano-delivery strategy for saquinavir (an anti-AIDS protease inhibitor) might be easily adapted to novel coronaviruses.

Chitosan, a naturally occurring polymer, was chosen for its immunogenicity and antibacterial properties. ${ }^{64}$ The cationic surface of chitosan is considered to contribute to its improved negative charge targeting ability. Furthermore, the polycationic nature of chitosan is believed to increase complement protein deposition on nanoparticles, resulting in macrophage absorption via complement receptors. ${ }^{65}$

At the moment, the only competitors are solid lipid nanoparticles. SLNPs have been studied for their potential as oral medicine carriers. ${ }^{39}$ These nanoparticles are primarily made of biocompatible, biodegradable, and physiological lipids, and they can also be used to deliver medications for a long time. Toxicity problems caused by polymeric nanoparticles can be avoided. In gastroenterology, lipid nanoparticles based on a solid matrix could be employed as medication carriers. Several drugs have low gastrointestinal (GI) absorption and oral bioavailability, ${ }^{39}$ particularly lipophilic compounds.
Lipid nanoparticles, Solid Lipid Nanoparticles, and Nanostructured Lipid Carriers are all nanocarrier systems in which surfactants maintain solid particles formed by a lipid matrix in an aqueous phase. This presents a challenging advantage for pulmonary applications, such as their potential use in pandemic outbreaks caused by respiratory illnesses, because they can be introduced into breathing carriers, allowing for deep lung deposition due to their small size, prolonged release, and low toxicity. ${ }^{39}$

Pfizer $\backslash$ Biontech and Moderna employed nano-lipids to push mRNA to the target in one of the most recently approved vaccinations. Indeed, BNT162b2 (Comirnaty ${ }^{\circledR}$; BioNTech and Pfizer) ${ }^{66}$ is a COVID-19-prevention nucleoside-modified mRNA vaccine coated in lipid nanoparticles. It encodes the SARS-CoV-2 spike protein, whose synthesis elicits immune responses against the antigen in recipients and is administered intramuscularly in a twodose regimen. ${ }^{68}$ RNA vaccines have one important benefit over DNA vaccinations: they do not require an additional transcription step in in-vivo systems. These nucleic acidbased vector vaccines are safe and simple to manufacture, but they require many doses and a unique delivery system ${ }^{67}$ because of their poor immunogenicity. We suggest and anticipate chitosan as a nano delivery technique to overcome this issue. Chitosan is a natural polymer that is cyto-compatible, bioresorbable, and biodegradable. It's one of the polymers approved by FDA. It's also an immune-regulating polysaccharide with great safety and antiviral action.

It has definite potential uses in the creation of antivirus software, as well as a bright future. We propose loading coronavirus protein onto polysaccharide-capped gold nanoparticles vaccines for COVID-19 treatment based on these exciting properties. However, there have been little attempts at research in this area thus far. Potential scaling-up and widespread manufacturing issues could have restricted its use while bolstering its growth. Indeed, adopting a polymeric carrier that is somewhat immunogenic makes the nanoparticles more visible to the immune system, allowing for more efficient phagocyte uptake. When compared to Solid Lipid Nanoparticles, these qualities provide a significant advantage in the utilization of chitosan nano-vehicles. Another noteworthy aspect of these nano-tools is that both nano-chitosan and viruses work at the same scale, making them particularly useful in vaccine development and immune engineering. Indeed, nanoengineered particles can replicate the structural and functional properties of viruses, making 
nanomedicine the best alternative to vaccine development technologies, not only for biopharmaceutical administration but also for evaluating therapeutic impact (eg, acting as nanotheranostic tools).

In addition, recent breakthroughs in nanotechnology have tremendously facilitated the development of novel vaccination delivery systems. Improving the efficacy with which mRNA vaccines and therapies are given is a vital step toward attaining their full potential. Because of the physical properties of nucleic acids, such as hydrophilicity and negative charge, ${ }^{68}$ passive diffusion through the plasma membrane is impossible. Furthermore, significant impediments to nucleic acid distribution exist, including interactions with serum proteins, endogenous nuclease degradation, and phagocyte internalization. ${ }^{68}$

As a result, a dependable delivery vehicle with effective cellular absorption and degradation resistance is required immediately. As a result, a nano-vehicle for vaccine delivery has been created. In fact, mRNA vaccines are made up of mRNA that carries the gene instructions for protein production inside SLNPs. After inoculation, SLNPs-mRNA is directed to the cytoplasm of host cells, where it is used as a template for protein antigen synthesis. ${ }^{69}$ The mRNA delivery mechanism in both the Moderna and Pfizer/BioNTech mRNA vaccines is lipid nanoparticles, with ionizable cationic lipid incorporated in the formulations. Synthetic cationic lipids produce solid lipid nanoparticles, which combine with polyanionic nucleic acids to form nanoscale compounds. ${ }^{69,70}$ Furthermore, given the quick creation and exceptional flexibility of mRNA vaccines to adapt to new potential virus variations, these vaccines have a promising future. ${ }^{71}$ Furthermore, given the competitive utilization of nanochitosan bearing immunogenicity, economic benefit, and biocompatibility superior to lipid nanoparticles, these vaccines can be expected to have a long future. There is confidence about the current and future candidates' chances of success.

Sex, age, ethnicity, and race, as well as fragile individuals like the immunocompromised and pregnant women, could all have an impact. It is clear that a single vaccine will not suffice in this situation. Alternative routes must be sought as a result. The use of nano-chitosan to transfer genetic information via a less expensive route of administration than the intramuscular route, which has been the standard for most vaccines up to now, is one example of this viewpoint. Indeed, the inherent cyto-compatibility, bioresorbability, and biodegradability of chitosan imply a natural extension of exceeding typical constraints. Oral vaccines, which have been used to treat respiratory infectious diseases, ${ }^{73}$ have a long history of successfully generating and activating the common mucosal immune system in nature. In light of these concerns, the use of chitosan as a natural nanocontainer for antiviral medicine delivery or the development of a potential new platform for vaccine administration via oral or oronasal routes should be studied.

Comirnaty vaccination appears to be effective against the Alpha, Beta, and Gamma Variant of COVID (VOCs), though to varied degrees, according to recent studies. The receptor binding area of the spike protein in the Delta form, on the other hand, has been associated to significant transmissibility and rapid spread in the Indian subcontinent. This raised worries about the variation's possible impact and ability to elude SARS-CoV-2 vaccines. Recent findings by certain researchers add to the growing body of data that an mRNA based (Comirnaty) vaccine is effective against known VOCs, highlighting the importance of vaccination. ${ }^{72}$ Despite this, additional research is needed in bigger populations to confirm the vaccine's efficacy against SARS-CoV-2 and new emerging variants such as Delta and Epsilon, while even more with antigenic drift's structural and functional ramifications in current SARS-CoV-2 variants. ${ }^{73}$ Finally, nano-vaccines could be viewed as a future strategic instrument for battling novel pandemics. In this approach, oral administration of chitosan therapeutic nanoparticles could be a viable alternative to intranasal or systemic coronavirus targeting.

\section{Conclusions and Outlook}

Nanotechnology has made significant progress in biomedical fields such as cancer therapy and other diseases, particularly during this difficult time when SARS-COV-2 has spread globally, infecting and killing millions of people, forcing governments to impose severe restrictions and emergency laws in order to contain the outbreak. It is vital to create nano-vaccines and nano-delivery systems aimed at battling and curing deadly corona viruses. The research and application of natural-derived nanoparticles such as chitosan has attracted a lot of attention in this field. The use of chitosan-derived nano-vectors holding medicines or drugs to cure and regulate COVID diffusion has made significant progress toward eradicating the virus. The treatment of COVID-19 with chitosan nano-derived tools and nano-vaccine can be considered a success. 


\section{List of Acronyms}

COVID-19, Coronavirus Infectious Disease-19; EGCG, Epigallocatechin gallate; NP, Nanoparticle; PLGA, poly(lactide-co-glycolide); PLA, polylactide; PGA, Polyglycolide; PCL, Polycaprolactone; FDA, Food and Drug Administration; SARS-CoV, severe acute respiratory syndrome coronavirus; HSPG, heparan sulfate proteoglycan; MERS-CoV, Middle East respiratory syndrome coronavirus; TEM, Transmission Electron Microscopy; FESEM, Field Emission Scanning Electron Microscopy; AFM, Atomic Force Microscopy; FTIR, Fourier-Transform Infrared Spectroscopy; XPS, X-Ray Particle Analysis; ART, Antiretroviral Therapy; TPP, Tripolyphosphate; HBV, Hepatitis B Virus; EVD, Ebola virus disease; DRC, Democratic Republic of Congo; ORFs, Open Reading Frames; WKV, whole-killed virus; mRNA, Messenger RNA; AD, Adenovirus; RBDs, Receptor Binding Domains; BPL, $\beta$-propiolactone; SLNPs, Solid lipid nanoparticles; HQ, Hydroquinone; RDV, Remdesivir; CQ, Chloroquine; HCQ, Hydroxychloroquine; EUA, Emergency Use Authorization; LO, Lopinavir; RI, Ritonavir; ARDS, Acute Respiratory Distress Syndrome; HIV-1, Human Immunodeficiency Virus1; IN, integrase protein; IMP, Importin; GI, Gastrointestinal; VOCs, Variants of COVID-19.

\section{Acknowledgments}

Authors gratefully acknowledge Department of Biological Sciences, Faculty of Science, Kuwait University for facilitating all means of support to perform research in nanodrug delivery in Kuwait and at CNR NANOTEC-Istituto di Nanotecnologia, Lecce, Italy.

\section{Disclosure}

The authors report no conflicts of interest for this work.

\section{References}

1. Shin MD, Shukla S, Chung YH, et al. COVID-19 vaccine development and a potential nanomaterial path forward. Nat Nanotechnol. 2020;15:646-655. doi:10.1038/s41565-020-0737-y

2. Nel AE. Nano-enabled COVID-19 vaccines: meeting the challenges of durable antibody plus cellular immunity and immune escape. ACS Nano. 2021;15(4):5793-5818. doi:10.1021/acsnano.1c01845

3. Yang D. Application of nanotechnology in the COVID-19 pandemic. Int J Nanomed. 2021;2021(16):623-649. doi:10.2147/IJN.S296383

4. Tang Z, Zhang X, Shu Y, Guo M, Zhang H, Tao W. Insights from nanotechnology in COVID-19 treatment. Nano Today. 2021;36: 101019. doi:10.1016/j.nantod.2020.101019

5. Tang Z, Na Kong N, Zhang X, et al. A materials-science perspective on tackling COVID-19. Nat Rev Mater. 2020;5(11):847-860. doi:10.1038/s41578-020-00247-y
6. Zhang Z, Tang Z, Farokhzad N, Chen T, Tao W. Sensitive, rapid, low-cost, and multiplexed COVID-19 monitoring by the wireless telemedicine platform. Matter. 2020;3(6):1818-1820. doi:10.1016/j. matt.2020.11.001

7. Ramana LN, Sharma S, Sethuraman S, Ranga U, Krishnan UM. Evaluation of chitosan nanoformulations as potent anti-HIV therapeutic systems. Biochim Biophys Acta. 2014;1840(1):476-484. doi:10.1016/j

8. Safer A-M, Leporatti S, Jose J, Soliman MS. Conjugation of EGCG and Chitosan NPs as a novel nano-drug delivery system. Int J Nanomedicine. 2019;14:8033-8804. doi:10.2147/IJN.S217898

9. Xue M, Hub S, Lu Y, et al. Development of chitosan nanoparticles as drug delivery system for a prototype capsid inhibitor. Int J Pharm. 2015;495:771-782. doi:10.1016/j

10. Akopova TA, Demina TS, Shchegolikhin AN, et al. Approach to design chitosan-polyester materials for biomedical applications. Int $J$ Polym Sci. 2012;2012(ID):827967. doi:10.1155/2012/ 827967

11. Zhang Z, Cui H. Biodegradability and biocompatibility study of poly (Chitosan-g-lactic Acid) Scaffolds. Molecules. 2012;17(3):32 43-3258. doi:10.3390/molecules 17033243

12. Martău GA, Mihai M, Vodnar DC. The Use of Chitosan, Alginate, and Pectin in the Biomedical and Food Sector-Biocompatibility, Bioadhesiveness, and Biodegradability. Polymers. 2019;11(11):18 37. doi:10.3390/polym 11111837

13. Chen X, Han W, Wang G, Zhao X. Application prospect of polysaccharides in the development of anti-novel coronavirus drugs and vaccines. Int J Biol Macromol. 2020;164(1):331-343. doi:10.1016/j. ijbiomac.2020.07.106

14. Yue Y, Shen M, Song Q, Xie J. Biological activities and pharmaceutical applications of polysaccharide from natural resources: a review. Carbohydr Polym. 2018;183(1):91-101. doi:10.1016/j.carbpol.2017. 12.009

15. Baraniuk C. Covid-19: what do we know about sputnik v and other Russian vaccines? Br Med J. 2021;372:n743. doi:10.1136/bmj.n743

16. Deborah K. archive.hshsl.umaryland.edu Novavax vaccine demonstrates strong immune response. Baltimore: University of Maryland; 2021.

17. Mahase E. How the Oxford-AstraZeneca covid-19 vaccine was made. BMJ. 2021;372:n86. doi:10.1136/bmj.n86

18. Remmel A. COVID vaccines and safety: what the research says. Nature. 2021;590:538-540. doi:10.1038/d41586-021-00290-x

19. Livingston EH, Malani PN, Creech CB. The Johnson \& Johnson Vaccine for COVID-19. JAMA. 2021;325(15):1575. doi:10.1001/jama.2021.2927

20. Mahase E. Covid-19: moderna vaccine is nearly $95 \%$ effective, trial involving high risk and elderly people shows. Br Med J. 2020;371: m4471. doi:10.1136/bmj.m4471

21. Chagla Z. In high-risk adults, the Moderna vaccine had $94 \%$ efficacy against COVID-19 $\geq 14 \mathrm{~d}$ after the 2nd dose. Ann Intern Med. 2021;174(3):JC28. doi:10.7326/ACPJ202103160-028

22. Noor R. Developmental Status of the Potential Vaccines for the Mitigation of the COVID-19 Pandemic and a Focus on the Effectiveness of the Pfizer-BioNTech and Moderna mRNA Vaccines. Curr Clin Microbiol Rep. 2021;3:1-8. doi:10.1007/ s40588-021-00162-y

23. Chirkov SN. The Antiviral Activity of Chitosan. Appl Biochem Microbiol. 2002;38:1-8. doi:10.1023/A:1013206517442

24. He X, Xing R, Liu S, et al. The improved antiviral activities of amino-modified chitosan derivatives on Newcastle virus. Drug Chem Toxicol. 2021;44(4):335-340. doi:10.1080/01480545

25. Cagno V, Tseligka ED, Jones ST, Tapparel C. Heparan Sulfate Proteoglycans and Viral Attachment: true Receptors or Adaptation Bias? Viruses. 2019;11:596. doi:10.3390/v11070596

26. Kalia M, Chandra V, Rahman SA, Sehgal D, Jameel S. Heparan Sulfate Proteoglycans Are Required for Cellular Binding of the Hepatitis E Virus ORF2 Capsid Protein and for Viral Infection. J Virol. 2009;83:12714-12724. doi:10.1128/JVI.00717-09 
27. Li J, Cai C, Ja L. Chitosan-Based Nanomaterials for Drug Delivery Molecules. 2018;23:2661. doi:10.3390/molecules23102661

28. Bhattarai N, Gunn J, Zhang M. Chitosan-based hydrogels for controlled, localized drug delivery. Adv Drug Deliv Rev. 2010;62 (1):83-99. doi:10.1016/j.addr.2009.07.019

29. Torabi N, Dobakhti F, Faghihzadeh S, Haniloo A. In vitro and in vivo effects of chitosan-praziquantel and chitosan-albendazole nanoparticles on Echinococcus granulosus Metacestodes. Parasitol Res. 2018;117(2015-2023):2015-2023. doi:10.1007/s00436

30. Jhaveri J, Raichura Z, Khan T, Momin M, Omri A. Chitosan Nanoparticles-Insight into Properties, Functionalization and Applications in Drug Delivery and Theranostics. Molecules. 2021;26:272. doi:10.3390/molecules26020272

31. Del Prado-Audelo ML, Caballero-Florán JH, Sharifi-Rad J, Mendoza-Muñoz N, González-Torres M, ZUrbán-Morlán Z. Chitosan-decorated nanoparticles for drug delivery. J Drug Deliv Sci Technol. 2020;59:01896. doi:10.1016/j.jddst.2020.101896

32. Mikušová V, Mikuš $P$. Advances in Chitosan-Based Nanoparticles for Drug Delivery. J.Mol.Sci. 2021;22:9652. doi:10.3390/ijms22179652

33. Wang G, Li R, Parseh B, Du G. Prospects, and challenges of anticancer agents' delivery via chitosan-based drug carriers to combat breast cancer: a review. Carbohydr Polym. 2021;268:118192. doi:10.1016/j.carbpol.2021.118192

34. Gulati N, Dua K, Dureja H. Role of chitosan based nanomedicines in the treatment of chronic respiratory diseases. Int J Biol Macromol. 2021;185:20-30. doi:10.1016/j.ijbiomac.2021.06.035

35. Safarzadeh M, Sadeghi S, Azizi M, Rastegari-Pouyani M, Pouriran R, Haji M. Chitin and chitosan as tools to combat COVID-19: a triple approach. Int J Biol Macromol. 2021;18 3:235-244. doi:10.1016/j.ijbiomac.2021.04.157

36. Krieser K, Emanuelli J, Moschini Daudt R, et al. Taste-masked nanoparticles containing Saquinavir for pediatric oral administration. Mater Sci Eng C. 2020;117:111315. doi:10.1016/j. msec.2020.111315

37. He S, Jacobsen J, Uhd Nielsen C, Genina N, Østergaard J, Mu H. Exploration of in vitro drug release testing methods for saquinavir microenvironmental $\mathrm{pH}$ modifying buccal films. Eur J Pharm Sci. 2021;163:105867. doi:10.1016/j.ejps.2021.105867

38. Ibrahim IM, Abdelmalek DH, Elshahat ME, Elfiky AE. COVID-19 spike-host cell receptor GRP78 binding site prediction. $J$ Infect. 2020;80(5):554-562. doi:10.1016/j.jinf.2020.02.026

39. Weber S, Zimmer A, Pardeike J. Solid Lipid Nanoparticles (SLN) and Nanostructured Lipid Carriers (NLC) for pulmonary application: a review of the state of the art. Eur J Pharm Biopharm. 2014;86 (1):7-22. doi:10.1016/j.ejpb.2013.08.013

40. Das S, Chaudhury A. Recent Advances in Lipid Nanoparticle Formulations with Solid Matrix for Oral Drug Delivery. AAPS PharmSciTech. 2011;12(1):62-76. doi:10.1208/s12249-010-95630

41. Mauthe M, Orhon I, Rocchi C, et al. Chloroquine inhibits autophagic flux by decreasing autophagosome-lysosome fusion. Autophagy. 2018;14(8):1435-1455. doi:10.1080/15548627.2018.1474314

42. Tang X-C, Agnihothram SS, Jiao Y, et al. Identification of human neutralizing antibodies against MERS-CoV and their role in virus adaptive evolution. Proc Natl Acad Sci USA. 2014;111(19):E2018E2026. doi:10.1073/pnas.1402074111

43. Wang M, Cao R, Zhang L, et al. Remdesivir and chloroquine effectively inhibit the recently emerged novel coronavirus $(2019-\mathrm{nCoV})$ in vitro. Cell Res. 2020;30(3):269-271. doi:10.1038/s41422-020-0282-0

44. Warren TK, Jordan R, Lo MK, et al. Therapeutic efficacy of the small molecule GS-5734 against Ebola virus in rhesus monkeys. Nature. 2016;531(7594):381-385. doi:10.1038/nature17180

45. Mulangu S, Dodd LE, Davey RT, et al. A randomized, controlled trial of Ebola virus disease therapeutics. $N$ Engl J Med. 2019;381 (24):2293-2303. doi:10.1056/NEJMoa1910993
46. Kujawski SA, Wong KK, Collins JP, et al. First 12 patients with coronavirus disease 2019 (COVID-19) in the United States. medRxiv. 2020;4:54.

47. Study to Evaluate the Safety and Antiviral Activity of Remdesivir (GS-5734 ${ }^{\mathrm{TM}}$ ) in Participants With Severe Coronavirus Disease (COVID-19). Available from: ClinicalTrials.gov. Identifier: NCT04292899

48. A Trial of Remdesivir in Adults With Severe COVID-19. Available from: ClinicalTrials.gov. Identifier: NCT04257656

49. Remdesivir [EUA Fact Sheet]. Foster City, CA: Gilead Sciences, Inc.; 2020. Available from: https://www.remdesivir.com/us/?gclid= EAIaIQobChMIv8LdnuqQ6gIVWx-. Accessed November 6, 2021.

50. Beigel JH, Tomashek KM, Dodd LE, et al. Remdesivir for the Treatment of Covid-19 - preliminary Report. N Engl J Med. 2020: NEJMoa2007764. Available from: http://www.nejm.org/doi/10.1056/ NEJMoa2007764.

51. Al Bari MAA. Targeting endosomal acidification by chloroquine analogs as a promising strategy for the treatment of emerging viral diseases. Pharmacol Res Perspect. 2017;5(1):e00293. doi:10.1002/ prp2.293

52. Savarino A, Boelaert JR, Cassone A, Majori G, Cauda R. Effects of chloroquine on viral infections: an old drug against today's diseases? Lancet Infect Dis. 2003;3(11):722-727. doi:10.1016/s1473-3099(03) 00806-5

53. Mehra MR, Desai SS, Ruschitzka F, Patel AN. Hydroxychloroquine or chloroquine with or without a macrolide for treatment of COVID-19: a multinational registry analysis. Lancet. 2020;S01406736(20)31180-6. doi:10.1016/S0140-6736(20)31180-6

54. Yao -T-T, Qian J-D, Zhu W-Y, Wang Y, Wang G-Q. A Systematic Review of Lopinavir Therapy for SARS Coronavirus and MERS Coronavirus-A Possible Reference for Coronavirus Disease-19 Treatment Option. J Med Virol. 2020;92(6):556-563. doi:10.1002/ jmv. 25729

55. Yang J, Zheng Y, Gou X, et al. Prevalence of comorbidities and its effects in patients infected with SARS-CoV-2: a systematic review and meta-analysis. Int $J$ Infect Dis. 2020;94:91-95. doi:10.1016/j. ijid.2020.03.017

56. Cao B, Wang Y, Wen D, et al. A Trial of Lopinavir-Ritonavir in Adults Hospitalized with Severe Covid-19. $N$ Engl J Med. 2020;382:1787-1799. doi:10.1056/NEJMoa2001282

57. Chan KS, Lai ST, Chu CM, et al. Treatment of severe acute respiratory syndrome with lopinavir/ritonavir: a multicentre retrospective matched cohort study. Hong Kong Med J. 2003;9(6):399-406. PMID: 14660806.

58. Chu CM, Cheng VCC, Hung IFN, et al. role of lopinavir/ritonavir in the treatment of SARS: initial virological and clinical findings. Thorax. 2004;59(3):252-256. doi:10.1136/thorax.2003.012658

59. Wagstaff KM, Rawlinson SM, Hearps AC, et al. An AlphaScreen ${ }^{\circledR}$ Based Assay for High-Throughput Screening for Specific Inhibitors of Nuclear Import. J Biomol Screen. 2011;16(2):192-200. doi:10.11 $77 / 1087057110390360$

60. Wagstaff KM. Ivermectin is a specific inhibitor of importin alpha/ beta- mediated nuclear import able to inhibit replication of HIV-1 and dengue virus. Biochem J. 2012;443(3):851-856. doi:10.1042/BJ20 120150

61. Caly L, Druce JD, Catton MG, Jans DA, Wagstaff KM. The FDA-approved drug ivermectin inhibits the replication of SARS-CoV-2 in T vitro. Antiviral Res. 2020;178:104787. doi:10. 1016/j.antiviral.2020.104787

62. Pelaz B. Diverse Applications of Nanomedicine. ACS Nano. 2017;11 (3):2313-2381.

63. Chen G, Roy I, Yang C, Prasad PN. Nanochemistry and Nanomedicine for Nanoparticle-based Diagnostics and Therapy. Chem Rev. 2016;116:2826-2885. doi:10.1021/acs.chemrev.5b00148 
64. Yang Y, Chen J, Li H, et al. Porcine interleukin-2 gene encapsulated in chitosan nanoparticles enhances immune response of mice to piglet paratyphoid vaccine. Comp. Immunol. Microbiol. Infect. Dis. 2007;30:19-32. doi:10.1016/j.cimid.2006.09.006

65. Johan B, Tengval P. Blood protein adsorption onto chitosan. Biomaterials. 2002;23:2561-2568. doi:10.1016/S0142-9612(01)00 391-X

66. Lamb YN. BNT162b2 mRNA COVID-19 Vaccine: first Approval. Drugs. 2021;81:495-501. doi:10.1007/s40265-021-01480-7

67. Hobernik D, Bros M. DNA Vaccines-How Far From Clinical Use? Int J Mol Sci. 2018;19:3605. doi:10.3390/ijms19113605

68. Jackson LA, Anderson EJ, Rouphael NG, et al. An mRNA Vaccine against SARS-CoV-2: preliminary Report. $N$ Engl J Med. 2020;383:1920-1931. doi:10.1056/NEJMoa2022483

69. Walsh EE, Frenck RW, Falsey AR, et al. Safety and Immunogenicity of Two RNA-Based Covid-19 Vaccine Candidates. $N$ Engl J Med. 2020;383:2439-2450. doi:10.1056/NEJMoa2027906

70. McKay PF, Hu K, Blakney AK, et al. Self-amplifying RNA SARS-CoV-2 lipid nanoparticle vaccine candidate induces high neutralizing antibody titers in mice. Nat Commun. 2020;11:3523. doi:10.1038/s41467-020-17409-9
71. Ramirez JEV, Sharpe LA, Peppas NA. Current state and challenges in developing oral vaccines. Adv Drug Deliv Rev. 2017;114:116-131. doi:10.1016/j.addr.2017.04.008

72. Liu Y, Liu J, Xia H, et al. BNT162b2-Elicited Neutralization against New SARS-CoV-2 Spike Variants. N Engl J Med. 2021;385:472-474. doi:10.1056/NEJMc2106083

73. Yuan M, Huang D, Lee C-C D, et al. Structural and functional ramifications of antigenic drifts in recent SARS-CoV-2 variants. Science. 2021;373:818-823. doi:10.1126/science.abh1139

74. Huang H, Fan C, Li M, et al. COVID-19: A Call for Physical Scientists and Engineers. ACS Nano. 2020;14:(4)3747-3754. doi: $10.1021 /$ acsnano.0c02618

75. Centers for Disease Control and Prevention (CDC). Credit: Eckert A, Higgins D. Available from: https://phil.cdc.gov/Details.aspx?pid= 23313. Accessed November 23, 2021.

76. Lapipette.Labs. COVID-19 vaccine cards; EnglishV1; 2021. Available from: https://lapipette.com/vaccine_cards. Accessed November 25, 2021.
International Journal of Nanomedicine

\section{Publish your work in this journal}

The International Journal of Nanomedicine is an international, peerreviewed journal focusing on the application of nanotechnology in diagnostics, therapeutics, and drug delivery systems throughout the biomedical field. This journal is indexed on PubMed Central, MedLine, CAS, SciSearch ${ }^{\mathbb{R}}$, Current Contents ${ }^{\mathbb{R}} /$ Clinical Medicine, $^{-}$

\section{Dovepress}

Journal Citation Reports/Science Edition, EMBase, Scopus and the Elsevier Bibliographic databases. The manuscript management system is completely online and includes a very quick and fair peer-review system, which is all easy to use. Visit http://www.dovepress.com/ testimonials.php to read real quotes from published authors. 